\title{
Pollinator effectiveness of a specialist bee exploiting a generalist plant — tracking pollen transfer by Heriades truncorum with quantum dots
}

\author{
Sabine Konzmann, Margareta Kluth, Deniz Karadana, Klaus Lunau \\ Institute of Sensory Ecology, Heinrich Heine University Düsseldorf, Universitätsstr. 1, 40225, Düsseldorf, Germany
}

Received 8 May 2019 - Revised 4 September 2019 - Accepted 9 October 2019

\begin{abstract}
Heriades truncorum (Megachilidae) is a specialist bee that forages on Asteraceae and collects pollen by tapping its abdomen on pollen-presenting florets which places the grains directly in the ventral scopa. We tracked pollen transfer by female $H$. truncorum between conspecific inflorescences of Inula ensifolia and Pulicaria dysenterica by labelling pollen with quantum dots. On average, bees transferred 31.14 (I. ensifolia) and 9.96 ( $P$. dysenterica ) pollen grains from the last visited inflorescence, $39 \%$ and $45 \%$ of which were placed on receptive styles. Pollen germination ratio is significantly lower for inflorescences of $P$. dysenterica visited by one $H$. truncorum $(0.13 \%)$ compared with open control inflorescences $(0.51 \%)$, which suggests that the bees mainly transfer self-pollen of these self-incompatible plants. Thus, a single visit by $H$. truncorum does not grant the plant high reproductive success, but the bees' abundance and flower constancy might reduce this disadvantage.
\end{abstract}

\section{Asteraceae / oligolecty / plant-pollinator interaction / pollen germination rate / single-visit deposition}

\section{INTRODUCTION}

Many mechanisms have evolved in angiosperms to secure reproductive success (reviewed in Pacini and Hesse 2004; Pacini and Dolferus 2016). Entomophilous plants face the dilemma that bees and other flower-visiting insects not only act as pollinators but also as pollen thieves, eating pollen or collecting it to feed their offspring (Thorp 1979). One strategy to enhance the chance of pollination is secondary pollen presentation, where pollen is placed on and presented by floral structures other than the anthers (Howell et al.

Electronic supplementary material The online version of this article (https://doi.org/10.1007/s13592-019-00700-0) contains supplementary material, which is available to authorized users.

Corresponding author: S. Konzmann, sabine.konzmann@uni-duesseldorf.de Manuscript editor: James Nieh
1993). In the plant family Asteraceae, the unreceptive style brushes or pumps pollen out of the florets through elongation (Erbar and Leins 1995, 2015). As the circularly arranged disc florets open successively, pollen is available continually and cannot be collected entirely in one flower visit. This pollen portioning strategy leads to more flower visitors collecting and possibly transferring pollen from one inflorescence. The adhesion of pollen grains to a flower visitor's body is mainly attributable to pollenkitt-a lipid-based substance covering pollen of most angiosperms - which also grants protection from adverse biotic and abiotic influences (reviewed in Pacini and Hesse 2005; Hesse 2010). Besides pollenkitt volume, pollen grain size and shape also affect the adhesion of entomophilous pollen grains (Lin et al. 2013).

Oligolectic bees are morphologically and behaviourally adapted to effectively collect pollen on their host plants (reviewed in Thorp 2000). 
Their foraging behaviour is fine-tuned to their host plants, e.g., adapted to continuous or synchronous pollen presentation (Schlindwein 2000), and the degree of specialisation can depend on the composition of plant species at a given locality (Schlindwein et al. 2009). In contrast to corbiculate bees (honey bees, bumble bees, stingless bees, and orchid bees) which use regurgitated nectar to form pollen pellets attached to their hind legs, non-corbiculate bees transport pollen either in their crop or in their scopa, a brush-like structure on their abdominal venter or long hairs on their hind legs (Michener 2007). Scopal pollen can be moistened or glazed, but is most often dry (Portman and Tepedino 2017). Apart from the fact that corbicular pollen is rather unlikely to detach from the compressed pellet, these modes of pollen storage (wet and compacted vs. dry and loose) affect pollen functionality differently: manual transfer of corbicular pollen of Apis and Bombus results in significantly lower seed numbers than scopal pollen of oligolectic bees, suggesting that enveloping the grains with moisture might also affect pollen viability (Parker et al. 2015).

Foraging on plants of the family Asteraceae, some oligolectic bees are known to collect pollen with an abdominal drumming, tapping, or wiping technique (Cane 2016). While contacting the pollen-presenting styles with the abdomen, pollen grains are directly placed into the scopa (Figure 1). The large-headed resin bee, Heriades truncorum (tribe Osmiini, Megachilidae), is a solitary bee which is endemic to central Europe and active from summer until early autumn (Westrich 1989). It forages exclusively on Asteraceae (Praz et al. 2008a) and collects pollen via abdominal drumming, a rapid dorso-ventral movement (Cane 2016; see supplementary material, Video S1, S2). Considering that this specialised behaviour is an adaptation for effective pollen collection from disc florets of Asteraceae, the effectiveness of pollen transfer to receptive stigmas is questionable. Although oligolectic bees may be more efficient pollinators than honey bees and bumble bees (e.g., Parker 1981), the complete opposite can also be the case. For instance, pollen-foraging females of the passion flower bee (Anthemurgus passiflorae,
Andrenidae) are thought to solely act as pollen thieves on their only host plant, Passiflora lutea (Passifloraceae) (Neff and Rozen 1995). Visitation frequency alone is no measure for pollination effectiveness of a flower visitor, but tracking the single-visit deposition (SVD) of conspecific pollen grains is a suitable means to provide information on pollinator effectiveness of any bee species (King et al. 2013).

As $H$. truncorum is morphologically and behaviourally adapted to efficiently collect pollen from inflorescences of Asteraceae, we expected the bees to transfer scarcely any pollen to receptive styles. The objective of our study was to test pollinator effectiveness of female $H$. truncorum foraging on inflorescences of Inula ensifolia and Pulicaria dysenterica (tribe Inuleae, Asteraceae) by tracking pollen grains labelled with quantum dots (Minnaar and Anderson 2019). Detecting marked pollen grains on the bees allowed identification of body sites that are potentially suitable for transferring pollen. Likewise, location of pollen placement on different floral structures could be specified after $H$. truncorum had visited an inflorescence with marked pollen grains. Viability of transferred pollen grains was measured by pollen tube germination.

\section{MATERIALS AND METHODS}

All experiments were conducted in the Botanical Garden of the Heinrich Heine University Düsseldorf from June to July 2018. In the vicinity of a nesting aid for wild bees that several females of Heriades truncorum were using, we placed ten abundantly flowering plants of each tested species, Inula ensifolia and Pulicaria dysenterica (Asteraceae). The average disc diameter was $9.95 \mathrm{~mm}( \pm 2.41 \mathrm{~mm} \mathrm{SD}, n=10)$ for $I$. ensifolia and $9.69 \mathrm{~mm}( \pm 1.25 \mathrm{~mm} \mathrm{SD}, n=$ 10) for P. dysenterica. Prior to testing, some inflorescences were covered with mesh fabric to prevent insect visits. Digital photographs and videos in the field were taken using a camera with a close-up lens (PEN E-PL7, M.Zuiko Digital ED $60 \mathrm{~mm}$ 1:2.8 Macro, Olympus, Japan). Seventeen video recordings with a frame rate of 30 frames/second were 


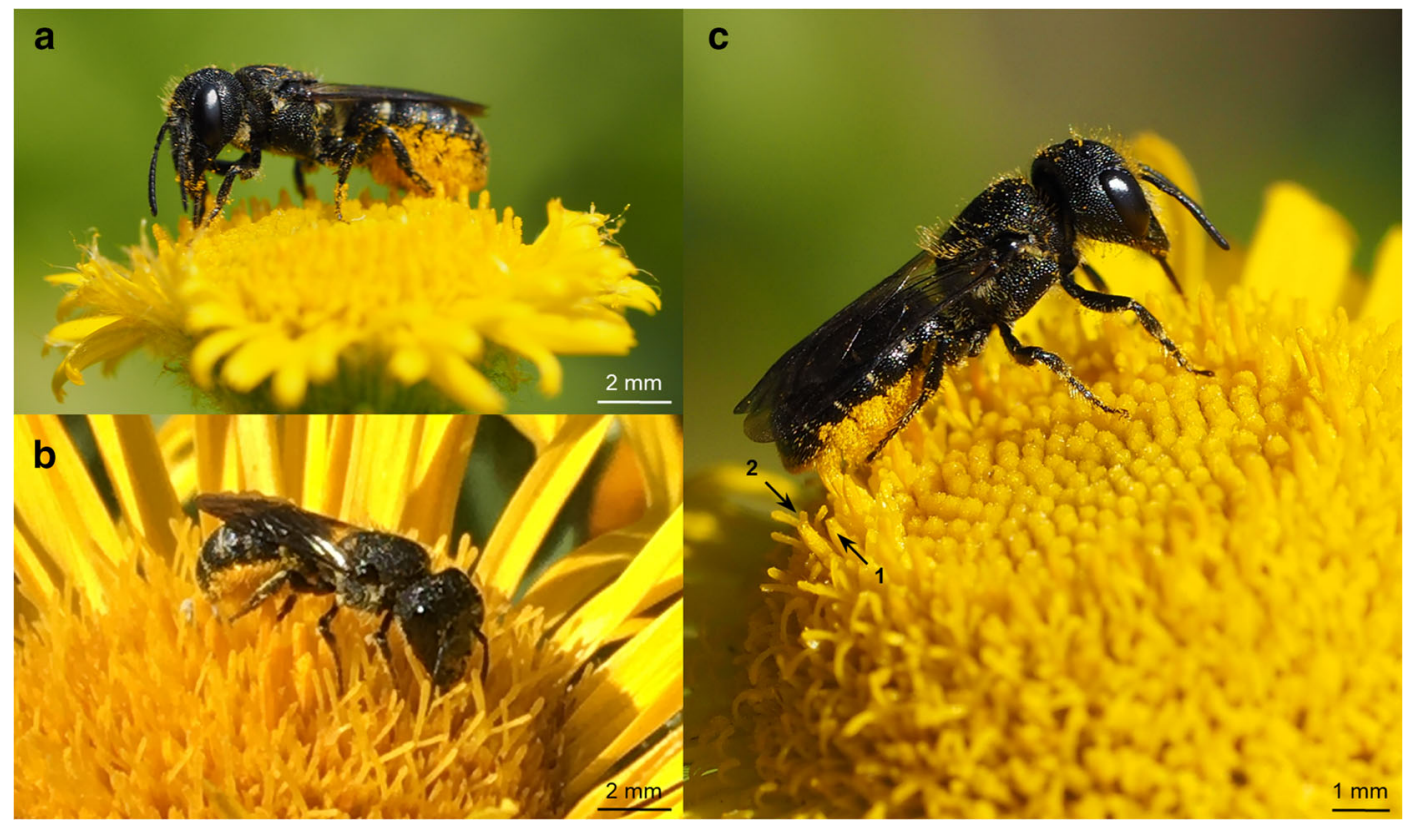

Figure 1. Female Heriades truncorum simultaneously drinking nectar and collecting pollen on inflorescences of Asteraceae. Pollen of (A) Pulicaria dysenterica and (B) Inula ensifolia is actively accumulated in the ventral scopa, but also clumps on legs and mouthparts while scattered grains can be found all over the bee's body. (C) Abdominal drumming of $H$. truncorum is specifically aimed at the circle of pollen-presenting florets in the male phase of anthesis (arrow 1), while receptive stigmas of florets in the female phase of anthesis (arrow 2) directly adjoin outside this circle.

slowed down to one-fourth speed to analyse drumming tempo by counting abdominal pats per minute.

\subsection{Quantum dots}

On selected inflorescences, pollen of all freshly opened florets (i.e., in the male phase of anthesis) was marked with quantum dots (Figure 2A,B). To apply quantum dots to pollen, they were mixed with hexane (5 $\mathrm{mg} / \mathrm{ml})$. Two microlitres of this solution were needed to cover all pollen grains of one floret in $I$. ensifolia and $1 \mu \mathrm{l}$ per floret in $P$. dysenterica. Quantum dots $\left(\mathrm{CuInSe}_{\mathrm{x}} \mathrm{S}_{2-\mathrm{x}} /\right.$ $\mathrm{ZnS}$ core/shell, UbiQD, Los Alamos, USA) are semiconductor nanoparticles that emit light of a specific colour (in this case with an emission peak at $620 \mathrm{~nm}$, orange) when exposed to UV light. A zinc-oleate complex as ligand causes them to bind to pollenkitt, making them suitable bio-labels without influencing pollen transport by bees (Minnaar and Anderson 2019). For visualization and quantitative evaluation of transferred quantum dots, bees or inflorescences were placed in an excitation box under a dissection microscope (setup slightly modified after Minnaar and Anderson 2019). The 3Dprinted box, which was made of polyamide 12 and varnished matte black, contained two LED lights (STS-DA1-1960B, 365 nm, 780 $\mathrm{mW}$, Nichia, Japan) as UV excitation source. Pollen grains labelled with quantum dots fluoresced and were viewed through a UVblocking, long-pass filter (blocking wavelengths $<400 \mathrm{~nm}, \mathrm{KV} 418,50 \times 50 \mathrm{~mm}$, Schott, Germany). Pictures of specimens under the dissecting microscope were taken with an ocular camera (DC.5000c, 5.0 MP, Euromex, Netherlands) in ambient light or with UV light exposure in the excitation box. 


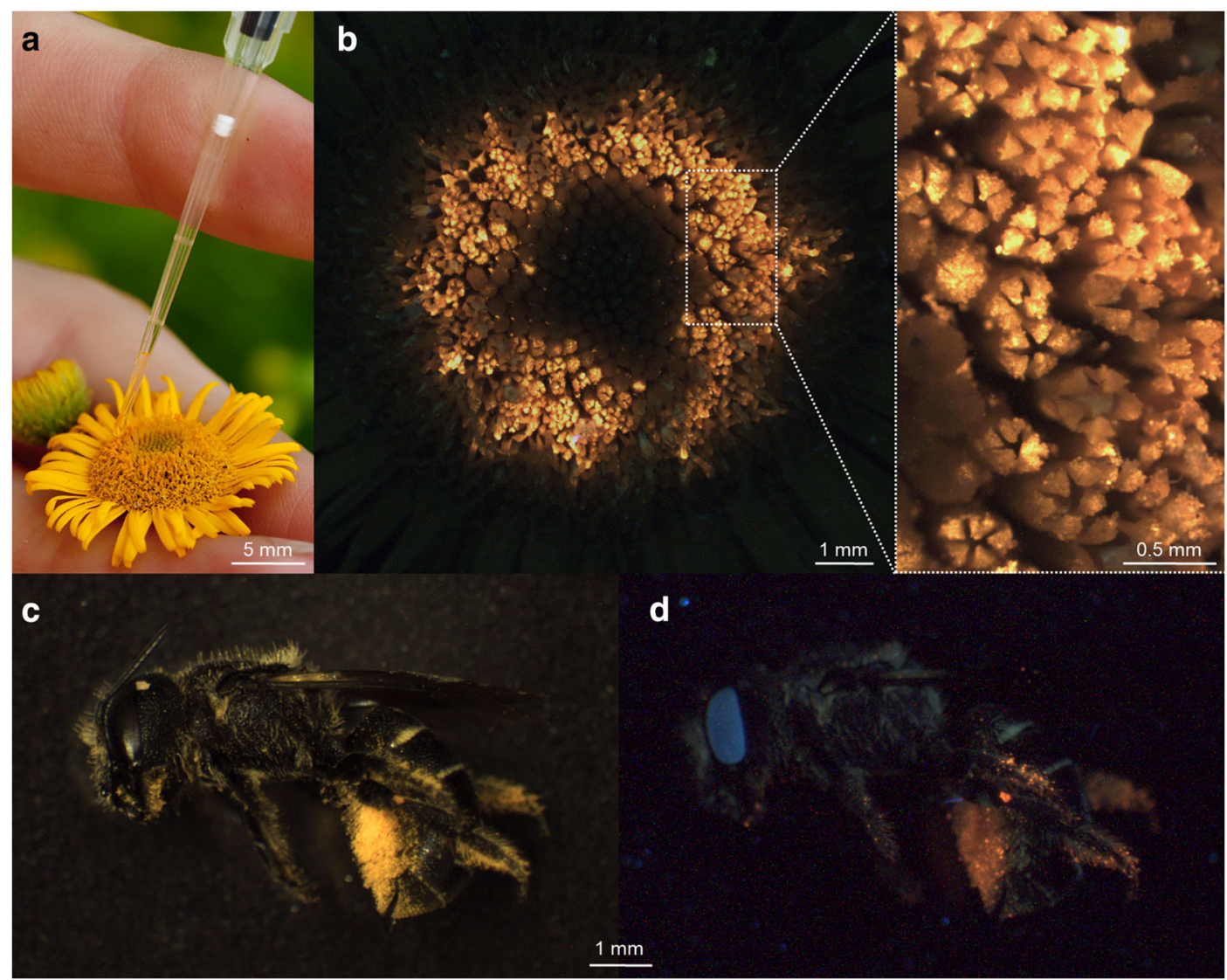

Figure 2. Tracking pollen grains of Pulicaria dysenterica with quantum dots. (A) One microlitre quantum dothexane solution was applied to each pollen-presenting floret on an inflorescence before a foraging Heriades truncorum was allowed to visit it. (B) Marked florets in male phase of anthesis (after bee visit) fluorescing under UV light exposure in the excitation box. (C) Female Heriades truncorum after foraging on an inflorescence previously marked with quantum dots, viewed in excitation box with ambient light and (D) with UV light; individual and aggregated pollen grains are mainly located in the scopa, on the tarsi, and on the mandibles.

\subsection{Transfer of marked pollen grains}

To test pollen transfer by H. truncorum, we prepared an inflorescence of $I$. ensifolia or $P$. dysenterica with quantum dots and allowed a female bee to forage on it. The next, untreated inflorescence the bee foraged on was examined for marked pollen in the excitation box. We counted fluorescing pollen grains located on receptive stigmas (disc florets in female phase of anthesis), on unreceptive, pollen-presenting stigmas (disc florets in male phase of anthesis), and on other floral structures (unopened disc florets, ray florets) (Figure 3A-C). The number of pollen grains occurring in clumps had to be estimated. Twenty-one inflorescences of I. ensifolia and 50 of $P$. dysenterica were analysed. Additionally, in 25 out of the 50 inflorescences of $P$. dysenterica, the landing site of the bee was marked to compare overall pollen transfer with transfer during landing. The landing site was defined by approximation as a circular area with a diameter of $7.96 \mathrm{~mm}$ which corresponds to the average length of a bee ( $\pm 0.76 \mathrm{~mm} \mathrm{SD}, n=18)$.

For each plant species, one bee was caught and immediately placed on ice after foraging on a 


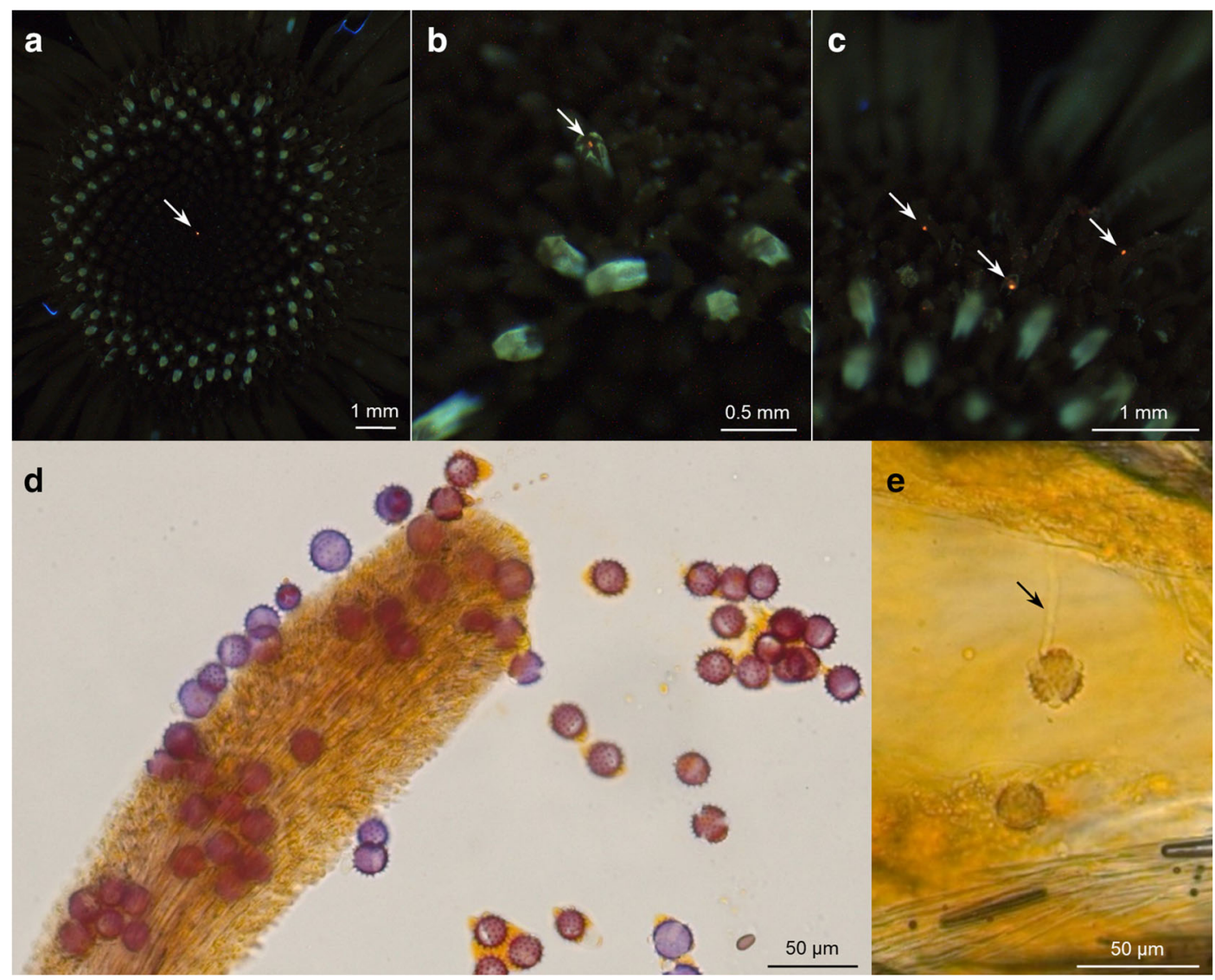

Figure 3. Inflorescences of Pulicaria dysenterica with pollen grains transferred during a single visit of Heriades truncorum. UV light exposure in the excitation box reveals fluorescing quantum dot-marked pollen grains (arrows) transferred from the previously visited inflorescence on (A) disc floret buds, (B) florets in male phase of anthesis, and $(\mathbf{C})$ florets in female phase of anthesis. Note that unmarked pollen grains and anther tubes of disc florets in female phase of anthesis autofluoresce (pale greenish colour). (D ) Stigma of a disc floret and pollen grains dyed with fuchsin gelatine in the pollen viability experiment (pollen grains not marked with quantum dots). Note that only pollen grains directly adhering to the stigma were counted; yellow, viscid material adhering to some of the grains is pollenkitt. (E) Germinating pollen tube (arrow) 3 days after pollen transfer.

marked inflorescence. Placement of marked pollen grains on the bee's body was examined in ambient light and under UV light exposure in the excitation box (Figure 2C,D).

\subsection{Viability of transferred pollen grains}

Tracking marked pollen grains from the previously visited inflorescence does not disclose information on the total amount and viability of pollen grains deposited by a bee. In an additional test series with unmarked pollen grains, inflorescences of $P$. dysenterica visited by $2-6$ female $H$. truncorum, inflorescences covered with mesh fabric to prevent any flower visits, and uncovered inflorescences freely available to all flower visitors were taken to the lab to exclude further flower visits. After 3 days allowing for pollen tube growth, we prepared stigmas from 12-20 florets per inflorescence (for 12 inflorescences per test series) with fuchsin gelatine and counted the number of adhering pollen grains and germinated pollen tubes (Figure 3D,E). The percentage of germinated pollen tubes was calculated 
by dividing the number of pollen tubes by the number of pollen grains multiplied by 100 .

\subsection{Statistical analysis}

All statistical analyses were performed using $\mathrm{R}$ statistical software, version 3.5.1 (R Core Team 2013). After testing normality of the data with Shapiro-Wilk tests, we applied Wilcoxon ranksum test (non-paired data) or Wilcoxon signedrank test (paired data) to compare two sets of nonparametric data. Multiple sets of data were analysed either with the Friedman test and Wilcoxon signed-rank test as a post hoc test (paired, non-parametric data), with KruskalWallis test and Wilcoxon rank-sum test (nonpaired, non-parametric data), or with ANOVA and Tukey's range test (non-paired, parametric data). Original data and a script of all statistical analyses are provided as supplementary material.

\section{RESULTS}

Observations showed that inflorescences of our test plants were visited by a variety of insects, from Coleoptera, Hemiptera, Thysanoptera, and Syrphidae, to various small $(<10 \mathrm{~mm})$ bee species. Out of the latter, the most abundant was Heriades truncorum, with both males and females frequenting the inflorescences. Analysis of video recordings revealed that female $H$. truncorum collect pollen on inflorescences of Pulicaria dysenterica with an average drumming tempo of 534 ( $\pm 93 \mathrm{SD}, n=17$ ) abdominal pats per minute (see supplementary material, Video $\mathrm{S} 1, \mathrm{~S} 2$ ).

Tracking quantum dot-marked pollen grains from the previously visited inflorescence showed that a bee deposited on average $31.14( \pm 25.49$ $\mathrm{SD}, n=21$ ) pollen grains on an inflorescence of Inula ensifolia. Significantly fewer pollen grains (Wilcoxon rank-sum test, $\mathrm{W}=845, p<0.001$ ) were transferred in $P$. dysenterica $(9.96 \pm 12.58$ $\mathrm{SD}, n=50$ ). Regarding the SVD of marked pollen grains on specific structures of an inflorescence, we found no aggregation of pollen grains on particular florets in P. dysenterica (Friedman test, $\chi^{2}=3.02$, df $=2, p=0.221$ ), whereas in $I$. ensifolia, more pollen per floret was placed on florets in the male phase of anthesis than on florets in the female phase of anthesis, disc floret buds, or ray florets (Friedman test, $\chi^{2}=7.72, \mathrm{df}=2, p=$ 0.021 , post hoc Wilcoxon signed-rank test) (Figure 4A,B). SVD of quantum dot-marked pollen grains per square millimetre did not differ in the approximate landing area and the total inflorescence area of $P$. dysenterica (Wilcoxon signed-rank test, $\mathrm{V}=74, p=0.154)$. On each receptive stigma of $P$. dysenterica, a bee deposited on average $0.04( \pm 0.07 \mathrm{SD}, n=50)$ pollen grains from the last visited inflorescence, which is only a fraction of the total amount of pollen transferred per receptive stigma $(20.63 \pm 24.83 \mathrm{SD}, n$ = 12) (Wilcoxon rank-sum test, $\mathrm{W}=600, p<$ $0.001)$. Significantly more pollen grains $(37.52 \pm$ 13.26 $\mathrm{SD}, n=12$ ) were found on receptive stigmas of inflorescences in the open control treatment and again significantly more $(226.01 \pm$ 38.54 SD, $n=12$ ) in the covered control (Kruskal-Wallis test, $\chi^{2}=28.06$, df $=2, p<$ 0.001 , post hoc Wilcoxon rank-sum test), in which no outcross-pollen could be transferred but self-pollen remained on each floret (Figure 4C). In contrast to this, the percentage of germinated pollen grains was lowest in the covered control $(0.00 \%)$, intermediate in inflorescences visited by one $H$. truncorum $(0.13 \%)$, and highest in the open control $(0.51 \%)$, differing significantly among all test series (ANOVA, $F=$ 20.13, $\mathrm{df}=2, p<0.001$, post hoc Tukey's range test) (Figure 4D).

\section{DISCUSSION}

The average amount of 534 abdominal pats per minute performed by female Heriades truncorum qualifies their pollen collection behaviour as abdominal drumming as it is even faster than the 467 pats/min previously recorded for Osmia spp. (Cane 2016). This highly specialised behaviour suggests that the bees effectively deprive the plants of their pollen. However, high efficiency of pollen collection is not restricted to specialised bees. Generalist bumble bees have been described to behaviourally adapt to a diversity of flowers in order to effectively collect pollen (Russell et al. 2017). Although H. truncorum females directly place pollen in their ventral scopa which entails 


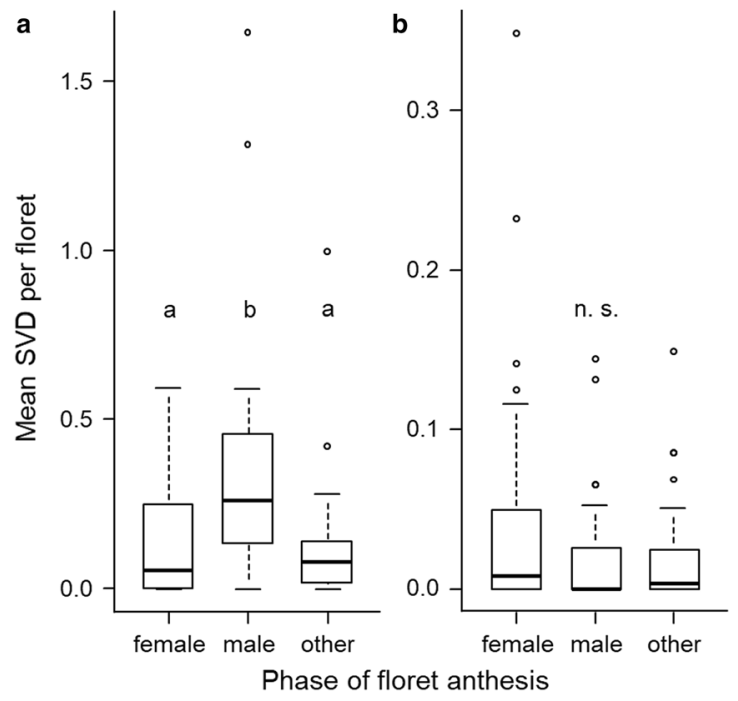

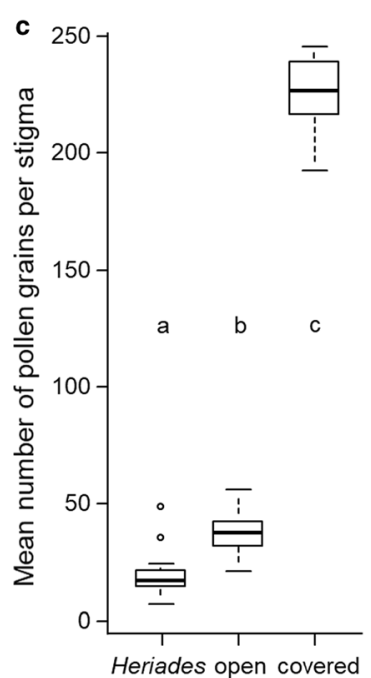

Test series

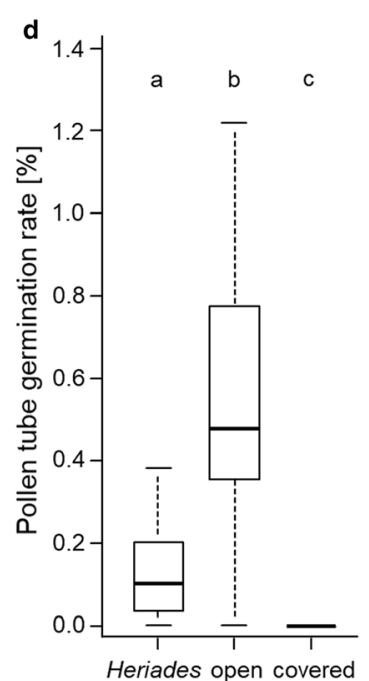

Test series

Figure 4. Pollen transfer and viability. (A,B ) Mean SVD (single-visit deposition) of quantum dot-marked pollen grains transferred from the previously visited inflorescence by a foraging female Heriades truncorum for (A) 21 inflorescences of Inula ensifolia and (B) 50 inflorescences of Pulicaria dysenterica. Phase of floret anthesis: female, disc florets with receptive styles; male, disc florets with pollen-presenting, unreceptive styles; other, ray florets and disc floret buds. (C,D ) Amount and viability of all transferred pollen grains in 3 test series, each with 12 inflorescences of $P$. dysenterica. Heriades, pollen transferred per individual during foraging (inflorescences visited by 2-6 female bees); open, inflorescence freely accessible to any insect visitors; covered, inflorescence hooded with mesh to prevent insect visits. (C) Mean number of pollen grains per receptive stigma either transferred by flower visitors (Heriades, open control) or produced by the same floret (covered control); (D ) pollen germination rate (\% of grain number). Different letters represent significant differences $(p<0.05)$ after $(\mathbf{A}, \mathbf{B})$ Friedman test and Wilcoxon signed-rank test, (C) Kruskal-Wallis test and Wilcoxon rank-sum test, or (D) ANOVA and Tukey's range test. Boxwhisker plots depict data distribution with median (thick line), data of 25th-75th percentile (= interquartile range, IQR; box), data of lower quartile minus $1.5 * \mathrm{IQR}$ and data of upper quartile plus $1.5 * \mathrm{IQR}$ (whiskers), and outliers (open dots). 
direct contact to receptive stigmas, the bees scarcely transfer outcross-pollen-signifying that the bees exploit the plants' pollen resources in exchange for poor cross-pollination service. In comparison, other bee species visiting inflorescences of Asteraceae are even less likely to transfer pollen from their transport structures as the grains are either agglutinated in the corbiculae, collected and transferred to a scopa located on the hind legs' femur and tibia without direct floral contact, or, as in Megachile centuncularis, transferred to a ventral scopa while lifting the abdomen to avoid floral contact (see supplementary material, Figure S1).

While female $H$. truncorum precisely contact the pollen-presenting florets with their abdomen which places most of the pollen grains directly in their scopa, fresh pollen can also be found on their legs, mainly the hind legs which pat the scopa to compact the pollen load (Figure 2C,D). This makes it impossible to identify whether pollen grains transferred to receptive stigmas originate from the scopa or the legs. Considering that in oligolectic bees, scopal pollen is as viable as body pollen (Parker et al. 2015), pollen from both scopa and legs of $H$. truncorum is suited to contribute to pollination. It has been reported that pollen placement on body sites that are accessible to the bee-as opposed to pollen placement on safe sites - can be advantageous for both plant and pollinator and possibly even enhance their mutualism (Tong and Huang 2018). Most Asteraceae benefit from openly offering pollen that is available to a multitude of flower visitors (and thus, many possible pollinators) which renders them independent of particular pollinator species. Many species-rich floral guilds are visited both by generalists and oligolectic bees (reviewed in Wcislo and Cane 1996; Minckley and Roulston 2006). Nevertheless, some species of Asteraceae and other plant families have been reported to possess chemically or structurally protected pollen that impedes digestion by nonspecialised bees (Müller and Kuhlmann 2008; Praz et al. 2008b).

Only a fraction of the pollen mass produced by a flower ultimately pollinates a conspecific flower, and the majority of pollen grains is lost in a variety of ways (reviewed in Minnaar et al. 2018).
One strategy to improve male reproductive success for plants is pollen partitioning. This can result in exclusive bee-plant interactions where only the specialised pollinator is granted a pollen reward (Siriani-Oliveira et al. 2018), but obligate mutual specialisations in plant-pollinator relationships are very rare (Cane 2018). In the generalist Asteraceae, pollen partitioning through successively opening florets ensures that not one single flower visitor like $H$. truncorum is able to exploit the entirety of pollen produced by the inflorescence.

Differences in pollen transfer from the last visited inflorescence in Inula ensifolia and Pulicaria dysenterica might be explained by their morphological characteristics. Very few pollen grains are transferred but evenly distributed on the rather flat discs with slightly protruding pollen-presenting styles of $P$. dysenterica. In contrast, the uneven disc structure of $I$. ensifolia presumably constitutes a larger area of contact for foraging $H$. truncorum, resulting in a higher amount of deposited grains, especially on florets in the male phase of anthesis. Aside from the inflorescence structure, population size can be an important factor influencing the number and proportion of conspecific pollen grains transferred in a self-incompatible plant species (Waites and Ågren 2004). The probability of a bee transferring foreign pollen (instead of self-pollen) is highest during landing and continually diminishes as the bee collects pollen from the inflorescence which covers previously acquired pollen (Muchhala and Thomson 2012; Minnaar et al. 2018). Contrary to expectations, the amount of labelled pollen grains deposited per square millimetre did not differ between the landing area and total disc area in $P$. dysenterica - the chances of cross-pollination are equal during landing and foraging.

A sufficient amount of conspecific and viable pollen grains must be deposited on receptive styles to ensure a high potential of full seed set and is therefore essential to characterise pollinator effectiveness (Ne'eman et al. 2010; King et al. 2013; Gorenflo et al. 2017). For instance, in selffertile cultivated red raspberries, two prolonged honey bee visits suffice to ensure pollination (Andrikopoulos and Cane 2018a), and singlevisit pollination efficacy is similar for honey bees, 
Bombus spp., and Osmia spp. (Andrikopoulos and Cane 2018b). Although solitary bees can still transfer fertile body pollen even after depositing pollen in their nest (Cane and Love 2018), pollen grains from recently visited flowers are more likely to contribute to pollination. Thus, single-visit deposition of quantum dot-marked pollen grains from the last visited inflorescence represents an approximation of the amount of foreign pollen transferred by female $H$. truncorum . This is consistent with the low germination rate of pollen transferred by H. truncorum compared with pollen transferred on open control inflorescences, which indicates that in contrast to less specialised flower visitors, $H$. truncorum mostly transfer pollen grains from the same inflorescence they are foraging on. For self-incompatible $P$. dysenterica, deposition of self-pollen does not constitute reproductive success (as indicated by $0 \%$ pollen germination in mesh-covered inflorescences). While pollinator efficiency of $H$. truncorum as regarded per inflorescence visit is rather poor, this does not take into account variables such as flower constancy and number of individuals. Floral host choice by oligolectic bees is probably strongly evolutionarily constrained (Sedivy et al. 2008). Within solitary bee species, females show higher floral constancy than males, but the males' longer flights positively affect the chances of cross-pollination (Ne'eman et al. 2006).

In conclusion, one inflorescence visit of the specialist bee $H$. truncorum that is adapted to effectively deprive Asteraceae flowers of their pollen scarcely contributes to the reproductive success of a generalist plant. Overall, the abundance and flower constancy of $H$. truncorum may positively affect their pollinator effectiveness.

\section{ACKNOWLEDGEMENTS}

We thank C. Minnaar and B. Anderson for help with the setup of the quantum dot method; the Botanical Garden of the University Düsseldorf, in particular A. Fischbach, for supplying test plants; O. Diestelhorst and B. Jacobi for helping to identify bees; and two anonymous reviewers for improving the manuscript.

\section{AUTHOR CONTRIBUTIONS}

KL conceived the study; SK, MK, and DK designed and performed the experiments and analysed the data; SK wrote the manuscript; and all authors revised the manuscript and approved the final manuscript.Funding information

This study was funded by the Deutsche Forschungsgemeinschaft (DFG; grant number F020511125).

\section{COMPLIANCE WITH ETHICAL STANDARDS}

Conflict of interest The authors declare that they have no conflict of interest.

\section{OPEN ACCESS}

This article is distributed under the terms of the Creative Commons Attribution 4.0 International License (http://creativecommons.org/licenses/by/4.0/), which permits unrestricted use, distribution, and reproduction in any medium, provided you give appropriate credit to the original author(s) and the source, provide a link to the Creative Commons license, and indicate if changes were made.

Efficacité de la pollinisation d'une abeille spécialiste exploitant une plante généraliste - suivi du transfert de pollen par Heriades truncorum par points quantiques.

Asteraceae / oligolecty / interaction plante-pollinisateur / taux de germination du pollen / dépôt à visite unique.

Die Bestäubungseffizienz einer spezialisierten Biene bei der Nutzung einer generalistischen Pflanze - der Nachweis von Pollentransfer durch Heriades truncorum mittels Quantumpartikel.

Asteraceae / Oligolektie / Pflanzen-BestäuberInteraktion / Pollenkeimungsrate / Einzelbesuchnachweis.

\section{REFERENCES}

Andrikopoulos C.J., Cane J.H. (2018a) Two prolonged bee visits suffice to maximize drupelet set for red raspberry, HortScience 53, 1404-1406. 
Andrikopoulos C.J., Cane J.H. (2018b) Comparative pollination efficacies of five bee species on raspberry, $\mathrm{J}$. Econ. Entomol. 111, 2513-2519.

Cane J.H. (2016) Specialist bees collect Asteraceae pollen by distinctive abdominal drumming (Osmia) or tapping (Melissodes, Svastra), Arthropod Plant Interact. 11, 257-261.

Cane J.H. (2018) Co-dependency between a specialist Andrena bee and its death camas host, Toxicoscordion paniculatum, Arthropod Plant Interact.. 12, 657-662.

Cane J.H., Love B. (2018) Pollen carryover between sequential foraging trips by a solitary bee: Implications for distant outcrossing, J. Pollinat. Ecol. 24, 136-143.

Erbar C., Leins P. (1995) Portioned pollen release and the syndromes of secondary pollen presentation in the Campanulales -Asterales -complex, Flora 190, 323338.

Erbar C., Leins P. (2015) Diversity of styles and mechanisms of secondary pollen presentation in basal Asteraceae - New insights in phylogeny and function, Flora 217, 109-130.

Gorenflo A., Diekötter T., van Kleunen M., Wolters V., Jauker F. (2017) Contrasting pollination efficiency and effectiveness among flower visitors of Malva sylvestris, Borago officinalis and Onobrychis viciifolia, J. Pollinat. Ecol. 21, 62-70.

Hesse M. (2010) Bonding single pollen grains together: How and why? in: von Byern J., Grunwald I. (Eds.), Biological adhesive systems, Springer-Verlag Wien, Vienna, pp. 3-13.

Howell G.J., Slater A.T., Knox R.B. (1993) Secondary pollen presentation in angiosperms and its biological significance, Aust. J. Bot. 41, 417-438.

King C., Ballantyne G., Willmer P.G. (2013) Why flower visitation is a poor proxy for pollination: measuring single-visit pollen deposition, with implications for pollination networks and conservation, Methods Ecol. Evol.. 4, 811-818.

Lin H., Gomez I., Meredith J.C. (2013) Pollenkitt wetting mechanism enables species-specific tunable pollen adhesion, Langmuir 29, 3012-3023.

Michener C.D. (2007) The bees of the world, The Johns Hopkins University Press, Baltimore.

Minckley R.L., Roulston T.H. (2006) Incidental mutualisms and pollen specialization among bees, in: Waser N.M., Ollerton J. (Eds.), Plant-pollinator interactions: from specialization to generalization, Chicago Press, Chicago, pp. 69-98.

Minnaar C., Anderson B. (2019) Using quantum dots as pollen labels to track the fates of individual pollen grains. Methods Ecol. Evol.. https://doi.org/10.1111 /2041-210X.13

Minnaar C., Anderson B., de Jager M.L., Karron J.D. (2018) Plant-pollinator interactions along the pathway to paternity, Ann. Bot. 20, 1-12.

Muchhala N., Thomson J.D. (2012) Interspecific competition in pollination systems: costs to male fitness via pollen misplacement, Funct. Ecol. 26, 476-482.
Müller A., Kuhlmann M. (2008) Pollen hosts of western palaearctic bees of the genus Colletes (Hymenoptera: Colletidae): the Asteraceae paradox, Biol. J. Linn. Soc. 95, 719-733.

Ne'eman G., Shavit O., Shaltiel L., Shmida A. (2006) Foraging by male and female solitary bees with implications for pollination, J. Insect Behav. 19, 383-401.

Ne'eman G., Jürgens A., Newstrom-Lloyd L., Potts S.G., Dafni A. (2010) A framework for comparing pollinator performance: effectiveness and efficiency, Biol. Rev. $85,435-451$.

Neff J.L., Rozen J.G. (1995) Foraging and nesting biology of the bee Anthemurgus passiflorae (Hymenoptera: Apoidea), descriptions of its immature stages, and observations on its floral host (Passifloraceae), Am. Mus. Novit. 3138, 19

Pacini E., Dolferus R. (2016) The trials and tribulations of the plant male gametophyte - understanding reproductive stage stress tolerance, in: Shanker A.K., Shanker C. (Eds.), Abiotic and biotic stress in plants, IntechOpen, London, https://doi.org/10.5772/61671

Pacini E., Hesse M. (2004) Cytophysiology of pollen presentation and dispersal, Flora 199, 273-285.

Pacini E., Hesse M. (2005) Pollenkitt - its composition, forms and functions, Flora 200, 399-415.

Parker A.J. (1981) How efficient are bees in pollinating sunflowers? J. Kansas Entomol. Soc. 54, 61-67.

Parker A.J., Tran J.L., Ison J.L., Bai J.D.K., Weis A.E., Thomson J.D. (2015) Pollen packing affects the function of pollen on corbiculate bees but not noncorbiculate bees, Arthropod Plant Interact. 9, 197-203.

Portman Z.M., Tepedino V.J. (2017) Convergent evolution of pollen transport mode in two distantly related bee genera (Hymenoptera: Andrenidae and Melittidae), Apidologie 48, 461-472.

Praz C.J., Müller A., Dorn S. (2008a) Host recognition in a pollen-specialist bee: evidence for a genetic basis, Apidologie 39, 547-557.

Praz C.J., Müller A., Dorn S. (2008b) Specialized bees fail to develop on non-host pollen: Do plants chemically protect their pollen? Ecology 89, 795-804.

R Core Team (2013) R: A language and environment for statistical computing, http://www.R-project.org. Accessed 23 Jan 2019.

Russell A.L., Buchmann S.L., Papaj D.R. (2017) How a generalist bee achieves high efficiency of pollen collection on diverse floral resources, Behav. Ecol. 28, 991-1003.

Schlindwein C. (2000) Behavioral adaptations of oligolectic bees to synchronous ant to continuous pollen presentation, in: Breckle S.W., Schweizer B., Arndt U. (Eds.), Ergebnisse weltweiter ökologischer Forschung, Günther Heimbach, Stuttgart, pp. 235-250.

Schlindwein C., Pick R.A., Martins C.F. (2009) Evaluation of oligolecty in the Brazilian bee Ptilothrix plumata (Hymenoptera, Apidae, Emphorini), Apidologie 40, 106-116. 
Sedivy C., Praz C.J., Müller A., Widmer A., Dorn S. (2008) Patterns of host-plant choice in bees of the genus Chelostoma: the constraint hypothesis of host-range evolution in bees, Evolution 62, 2487-2507.

Siriani-Oliveira S., Oliveira R., Schlindwein C. (2018) Pollination of Blumenbachia amana (Loasaceae): flower morphology and partitioned pollen presentation guarantee a private reward to a specialist pollinator, Biol. J. Linn. Soc. 124, 479-491.

Thorp R.W. (1979) Structural, behavioral, and physiological adaptations of bees (Apoidea) for collecting pollen, Ann. Mo. Bot. Gard. 66, 788-812.

Thorp R.W. (2000) The collection of pollen by bees, Plant Syst. Evol.. 222, 211-223.

Tong Z.Y., Huang S.Q. (2018) Safe sites of pollen placement: a conflict of interest between plants and bees? Oecologia 186, 163-171.
Waites A.R., Ågren J. (2004) Pollinator visitation, stigmatic pollen loads and among-population variation in seed set in Lythrum salicaria, J. Ecol. 92, 512-526.

Wcislo W.T., Cane J.H. (1996) Floral resource utilization by solitary bees (Hymenoptera: Apoidea) and exploitation of their stored foods by natural enemies, Annu. Rev. Entomol. 41, 257-286.

Westrich P. (1989) Die Wildbienen Baden-Württembergs, Eugen Ulmer Verlag, Stuttgart.

Publisher's note Springer Nature remains neutral with regard to jurisdictional claims in published maps and institutional affiliations. 